\title{
Papers
}

\section{ATM protein synthesis patterns in sporadic breast cancer}

\author{
R Kairouz, R A Clarke, P J Marr, D Watters, M F Lavin, J H Kearsley, C Soon Lee
}

\begin{abstract}
Aims-The gene mutated in ataxiatelangiectasia (A-T), designated ATM (for "A-T mutated"), is believed to be associated with an increased risk of developing breast cancer. Most patients with A-T have null mutations of the ATM gene that appear to give rise to a truncated nonfunctional ATM protein. Therefore, the increased risk of breast cancer reported in A-T heterozygotes appears to be the result of haplo-insufficiency of ATM in breast tissues. This study aimed to determine whether reduced synthesis of ATM was also an important factor in sporadic breast cancer.
\end{abstract}

Methods-Paraffin wax embedded tissues from patients with breast invasive ductal carcinoma (IDC) $(n=42)$, patients with ductal carcinoma in situ (DCIS) $(\mathbf{n}=17)$, and others with lymph node metastases (n=14) were studied. A streptavidinbiotin-peroxidase system was used to stain tissue sections for the ATM protein using the ATM-4BA and CT-1 polyclonal and monoclonal antibodies, respectively. The protein truncation test was used to screen for mutations in the ATM gene in those patients who had greatly reduced ATM protein immunoreactivity in the primary carcinoma $(n=3)$.

Results-Most metastatic breast carcinomas in lymph nodes (71\%) had greatly reduced or absent ATM protein synthesis, which was significant when compared with that observed in non-metastatic invasive breast carcinomas $\left(\mathbf{p}=0.029 ; \chi^{2}\right.$ test). Although not significant $(\mathrm{p}=\mathbf{0 . 0 4 5}$; $\chi^{2}$ test), some sporadic breast carcinomas (14 of 42) also had reduced or absent ATM protein immunoreactivity. The protein truncation test did not reveal any gross ATM gene abnormality in the cases tested, indicating that the patients were not $A-T$ heterozygotes, who are predisposed to breast cancer.

Conclusions-A reduction in immunohistochemically detectable ATM protein in sporadic breast carcinoma implicates ATM in the progression of the disease. (f Clin Pathol: Mol Pathol 1999;52:252-256)

Keywords: breast carcinoma; ATM gene; metastases; tumour suppressor
Ataxia-telangiectasia (A-T) is an autosomal recessive disorder characterised by progressive ataxia, immunodeficiency, neurological abnormalities, hypersensitivity to ionising radiation, and predisposition to cancer. ${ }^{1-4} \mathrm{~A}-\mathrm{T}$ homozygotes have a severalfold increased risk of cancer ${ }^{5}$ and there is also some evidence for increased cancer predisposition in A-T heterozygotes. ${ }^{1-5}$ The most distinct association has been with breast tumours, where blood relatives of patients with A-T have up to five times the risk of developing breast cancer relative to their spouse controls. ${ }^{1-5}$ The increased risk of developing breast cancer in A-T heterozygotes was substantiated by Athma et al using haplotype analysis to identify female relatives of patients with A-T who carry the mutation. ${ }^{6}$ Design limitations in these studies based on A-T heterozygote prevalence, information on relative risk, and size of populations selected preclude a precise estimate of risk at this stage. ${ }^{78}$ However, considering the relatively low incidence of $\mathrm{A}-\mathrm{T}$, it was not surprising to find that the frequency of A-T truncation mutations in women with early onset breast cancer is no greater than in otherwise normal control women. ${ }^{78}$

The ATM (A-T mutated) gene is involved in signal transduction and the cell cycle checkpoint response to DNA damage. ${ }^{9-11}$ The ATM gene encodes a protein of 3056 amino acids with a molecular weight of $350 \mathrm{kDa} .{ }^{12}$ ATM gene mutations result in defective G1-S checkpoint control of the cell cycle that is mediated through the p53, p21/cip1, cyclin dependent kinases, and retinoblastoma protein signal transduction pathway. ${ }^{1011}{ }^{13}$ Most patients with A-T have null mutations of the ATM gene that are predicted to give rise to protein truncation, resulting in the failure of production of functional ATM protein. ${ }^{14-16}$ In breast tumours, high levels of loss of heterozygosity (LOH) have been demonstrated at loci flanking the ATM gene, ${ }^{17}$ although Vorechovsky et al failed to find any somatic mutations in 38 sporadic breast tumours tested. ${ }^{18}$

In our study, we describe the immunohistochemical analysis of the ATM protein in sporadic breast cancers. Polyclonal and monoclonal antibodies ${ }^{19}$ were used to investigate the level of ATM immunoreactivity in normal, premalignant, invasive, and metastatic breast tissue.
Accepted for publication 22 June 1999 


\section{Materials and methods}

TISSUE PREPARATION

Paraffin wax embedded, archival tissues from patients with breast invasive ductal carcinoma (IDC) ( $\mathrm{n}=42), 17$ of which also demonstrated ductal carcinoma in situ (DCIS) $(n=17)$, and 14 of which were accompanied by lymph node metastases $(n=14)$ were studied. Histologically normal breast tissues with ductal epithelium and acini $(n=42)$ were obtained from areas of the breast specimens located away from the primary tumour masses, and were used as non-neoplastic controls. The study population comprised 42 women aged 36 to 91 years who had therapeutic surgical mastectomies with axillary clearances for histologically confirmed breast carcinomas. The tissues were obtained during operative surgery and routine diagnostic pathological examination. No procedures were performed solely for research purposes. Adequate clinical follow up information was available in 15 patients with breast carcinoma.

\section{ANTI-ATM ANTIBODIES}

The ATM polyclonal antibody, ATM-4BA, has been characterised previously. ${ }^{19}$ ATM-4BA was raised in rabbits against a recombinant protein spanning amino acids 2323-2740 of the full length ATM protein. The anti-ATM monoclonal CT-1 was raised in mice against a synthetic peptide corresponding to a 16 amino acid ATM fragment from the extreme C-terminus of the ATM protein (G Birrell, 1997, unpublished data). Western analyses using the CT-1 monoclonal antibody and the ATM-4BA polyclonal antibody detect a single protein band of $\sim 350 \mathrm{kDa}$ in normal but not A-T (homozygous null mutations) lymphoblastoid cell lines (fig 1).

\section{IMMUNOHISTOCHEMISTRY}

A standard streptavidin-biotin method was used for immunohistochemistry, as described previously. ${ }^{20}$ Briefly, tissue sections were cut at $4 \mu \mathrm{m}$, mounted on glass slides, and air dried overnight. Adjacent sections were used, one section for immunostaining and the other as a control. After blocking of endogenous peroxi-

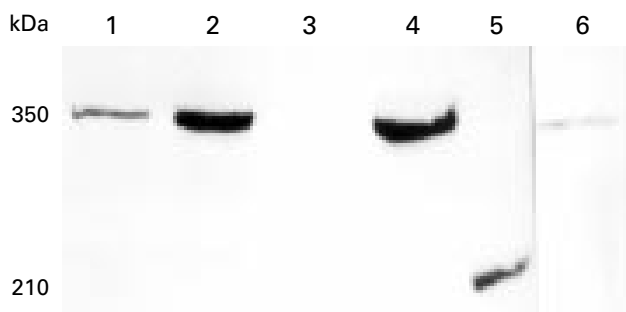

Figure 1 Western analysis of protein extracts from white blood cells using polyclonal ATM-4BA and monoclonal CT-1 antibodies, which detect a single protein band of $\sim 350 \mathrm{kDa}$ in normal (lanes 1, 2, 4, and 6) but not ataxia-telangiectasia (A-T) lymphoblastoid cell lines (lane 3). Lane 1, ATM-4BA against cells from normal control individual. Lane 2,

ATM-4BA against cells from normal control individual after mitogenic stimulation. Lane 3, ATM-4BA against cells from patient with $A-T$. Lane 4, ATM-4BA against cells from normal control individual after mitogenic stimulation. Lane 5, molecular weight standard. Lane 6, CT-1 against cells from normal control individual. dase, washing in Tris/ $\mathrm{HCl}$ saline, $\mathrm{pH} \mathrm{7.6,} \mathrm{and}$ blocking of non-specific binding of antibodies with skimmed milk solution, tissue sections were incubated overnight with the primary antibodies to ATM: ATM-4BA (1/100 dilution) and CT-1 (1/10 dilution). The primary antibodies were detected with a labelled streptavidin-biotin-peroxidase system. In sections used as negative controls, the primary antibodies were substituted with skimmed milk solution. The sections were counterstained with Harris haematoxylin.

ASSESSMENT OF IMMUNOHISTOLOGICAL STAINING The immunohistochemical staining of cells was assessed according to both the intensity and proportion of cells stained. ATM protein synthesis in a tumour section was classified as reduced if immunostaining was weak in intensity and less than $50 \%$ of cells stained positive when compared with the corresponding normal appearing breast ductal epithelium. The invasive ductal carcinomas were graded according to the method of Elston and Ellis. ${ }^{21}$

\section{STATISTICAL ANALYSIS}

Categorical variables were analysed with the $\chi^{2}$ contingency test. Only $\mathrm{p}$ values $<0.05$ were considered significant.

\section{THE PROTEIN TRUNCATION TEST (PTT)}

Three patients shown here to have a significant reduction or absence of ATM immunoreactivity in breast neoplasms were tested for A-T heterozygosity by applying the PTT to samples of their blood, as described previously. ${ }^{22}{ }^{23}$ In summary, RNA was extracted from peripheral blood lymphocytes and followed by reverse transcription-polymerase chain reaction (RTPCR) amplification of eight overlapping regions spanning the $9.9 \mathrm{~kb}$ ATM open reading frame. ${ }^{9}$ Forward PCR primers included a T7 promoter and a translation initiation codon to direct a coupled transcription translation reaction. ${ }^{24} 35$ $S$ methionine (Amersham, Little Chalfont, Buckinghamshire, UK) was incorporated into translation products, followed by electrophoretic separation ( 16 hours at $150 \mathrm{~V}$ ) on a $14 \%$ sodium dodecyl sulphate (SDS) polyacrylamide gel. The gel was dehydrated and rinsed in demineralised water. It was subsequently dried and autoradiographed at $-70^{\circ} \mathrm{C}$, initially for two hours, then for 16 hours using Kodak $\mathrm{X}-\mathrm{Omat}$ scientific imaging film.

\section{Results}

\section{NORMAL BREAST TISSUE}

Using the polyclonal ATM-4BA antibody, strong ATM protein immunoreactivity was found in most of the areas with non-neoplastic, normal appearing breast tissue (36 of 42) (fig 2A). None of the samples had areas in which the normal ductal epithelium did not show ATM protein immunoreactivity (table 1). There were six other samples (six of 42) that had reduced ATM protein immunostaining in the normal ductal epithelium, and these were also associated with reduced staining in the corresponding carcinomas. Strong immunostaining was seen in 29 of 36 samples in the 

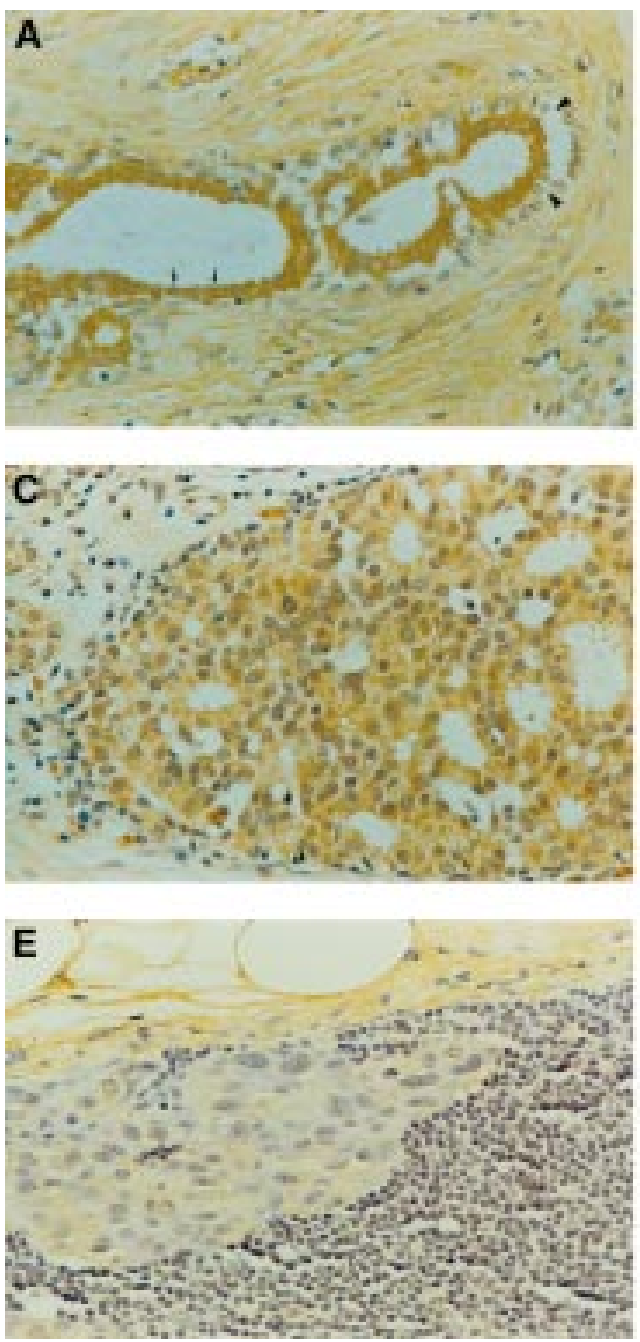

cytoplasm of cells within the inner epithelial layer of normal ducts, whereas seven of 36 showed nuclear staining. There was some variation in the intensity and extent of the immunostaining. However, the myoepithelial cells did not stain for the protein.

In support of the specificity of ATM-4BA immunostaining, a similar pattern of staining was seen using the ATM monoclonal antibody, CT-1, where immunoreactivity was also found in most of the areas with non-neoplastic, normal appearing breast tissue. CT-1 immunostaining was mostly in the cytoplasm of cells, within the inner epithelial layer of normal ducts, although some samples also had nuclear staining, as has been shown in a previous study. ${ }^{25}$

DUCTAL CARCINOMA IN SITU

Most of the DCIS samples (13 of 17) displayed strong ATM protein immunoreactivity using the ATM-4BA antibody (fig 2B; table 1). Only three

Table 1 ATM (ataxia-telangiectasia mutated) immunoreactivity in breast carcinoma

\begin{tabular}{lllll}
\hline & & \multicolumn{3}{l}{ Immunoreactivity } \\
\cline { 3 - 5 } Diagnosis & Number & Nil & Weak & Strong \\
\hline Normal breast ducts & 42 & 0 & 6 & 36 \\
Ductal carcinoma in situ & 17 & 1 & 3 & 13 \\
Invasive ductal carcinoma & 42 & 1 & 13 & 28 \\
Lymph node metastasis & 14 & 4 & 6 & 4 \\
\hline
\end{tabular}
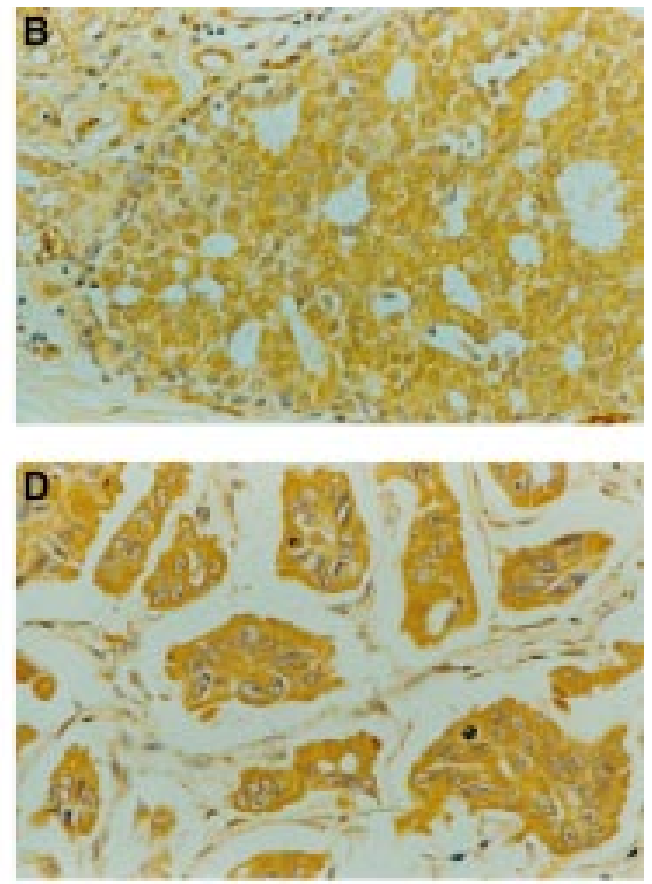

Figure 2 (A) Strong ATM (ataxia-telangiectasia mutated) protein immunoreactivity in the inner epithelial cells (small arrows) of a normal breast duct detected by a polyclonal antibody to the protein. The outer myoepithelial cells are negative (large arrows) (immunoperoxidase, ATM-4BA). (B) Strong immunostaining for the ATM protein in ductal carcinoma in situ (DCIS)

(immunoperoxidase, ATM-4BA). (C) An almost identical pattern of strong immunostaining of a duct with DCIS, using the monoclonal antibody CT-1 (immunoperoxidase, CT-1). (D) Strong ATM protein immunoreactivity in an invasive ductal carcinoma of the breast (immunoperoxidase; ATM-4BA). (E) Loss of ATM protein immunoreactivity in metastatic breast carcinoma (immunoperoxidase; ATM-4BA). All magnifications, $\times 200$.

of the DCIS samples (three of 17) showed reduced ATM protein immunostaining and a single case (one of 17) had no ATM staining. The staining pattern was similar to that seen with the non-neoplastic, normal appearing breast ductal epithelium. The monoclonal antibody CT-1 showed identical staining (fig 2C).

INVASIVE DUCTAL CARCINOMA

Twenty eight of 42 IDC samples had strong immunoreactivity (fig 2D). On the other hand, a large proportion of IDC samples (14 of 42) had greatly reduced or absent ATM protein immunoreactivity. Of these samples, one of 42 had no evidence of ATM protein immunoreactivity (table 1). There was also variation in the intensity and extent of the immunostaining, with some areas of the tumour showing a large reduction or absence of staining.

LYMPH NODE METASTASES

Four of 14 axillary nodes with metastases showed strong ATM immunoreactivity. However, most metastases (10 of 14) displayed a large reduction or absence of ATM protein immunohistological staining (fig 2E). Six of these 14 cases had a large reduction in ATM protein immunoreactivity, whereas four of the 14 cases showed no immunostaining. 
Table 2 Intracase analysis of ATM (ataxia-telangiectasia mutated) immunoreactivity in breast carcinoma

\begin{tabular}{llr}
\hline & \multicolumn{2}{c}{ Primary IDC } \\
\cline { 2 - 3 } & Strong & Weak \\
\hline Metastasis $(\mathrm{n}=14)$ & & \\
$\quad$ Strong & $29 \%$ & $0 \%$ \\
$\quad$ Weak/Nil & $29 \%$ & $42 \%$ \\
DCIS ( $=17)$ & $68 \%$ & $13 \%$ \\
$\quad$ Strong & $0 \%$ & $19 \%$ \\
$\quad$ Weak/Nil & & \\
\hline
\end{tabular}

DCIS, ductal carcinoma in situ; IDC, invasive ductal carcinoma.

There was a consistent trend towards reduced ATM production in more invasive stages (table 1). There was no individual case where ATM immunoreactivity was weak in the DCIS sample and strong either in the invasive tumour or metastatic sample. Furthermore, none of the cases showed weak ATM immunostaining in the primary tumour and strong staining in the metastasis.

The difference in the immunohistological staining for the ATM protein between normal breast ducts and invasive carcinoma was not significant $\left(\mathrm{p}=0.073 ; \chi^{2}\right.$ with continuity correction). Similarly, there was no significant difference between DCIS and invasive carcinoma of the breast $\left(\mathrm{p}=0.67 ; \chi^{2}\right.$ with continuity correction). However, the differences in ATM production between primary carcinoma and metastatic carcinoma in the lymph nodes was significant $\left(\mathrm{p}=0.029 ; \chi^{2}\right.$ with continuity correction)

INTRACASE ANALYSIS OF ATM PRODUCTION IN BREAST CARCINOMA

To determine ATM production in tumour progression and metastasis, intracase comparisons between premalignant DCIS and invasive primary carcinoma tissues and between primary carcinomas and metastases in lymph nodes were made (table 2). This method of assessment obviates any problem associated with immunostaining as a result of different fixation times for the specimens.

We found that in most cases cases (68\%), strong ATM immunoreactivity was found in the areas with both DCIS and invasive

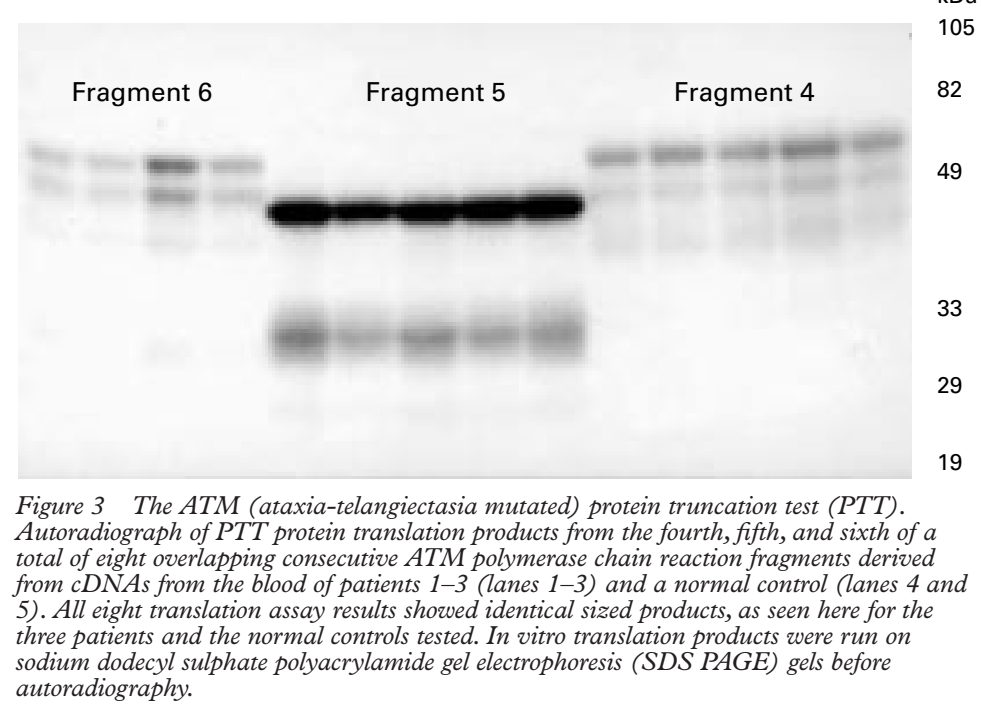

carcinoma. Thirteen per cent had strong ATM staining in the DCIS areas, which was weak or absent in the primary invasive ductal carcinoma areas, and $19 \%$ had reduced or absent ATM immunostaining in both DCIS and primary IDC areas.

In contrast, of the 14 cases with lymph node metastases, strong ATM immunoreactivity in both the metastasis and primary carcinoma tissues was found in only a small number of the cases $(29 \%)$. However, a similar but significant proportion of cases $(29 \%)$ had strong immunostaining in the primary carcinomas but reduced or absent ATM expression in the metastases. Decreased or no staining in both primary carcinoma and metastasis was seen in $42 \%$ of cases (table 2).

There were no individual cases where ATM immunoreactivity was weak in the DCIS areas and strong in either the primary carcinoma or metastasis. Furthermore, none of the cases showed weak ATM immunostaining in the primary carcinoma and strong staining in the metastasis.

\section{ATM MUTATIONS}

Three patients selected on the basis of a large reduction in ATM gene expression in breast carcinoma tissues had their blood DNA tested for ATM mutations. These three patients displayed normal length RT-PCR products for the eight overlapping ATM fragments (results not shown). This indicated that there were no gross anomalies such as deletions, duplications, or splicing mutations. Furthermore, the in vitro PTT translation products derived from these eight overlapping PCR products were identical to normal length protein products, indicating that none of the patients had translation terminating mutations in the ATM protein (fig 3). These PTT results indicated that these three patients with breast cancer were not A-T heterozygotes with a predisposition for breast cancer or reduced ATM synthesis.

\section{Discussion}

In our study, ATM synthesis in normal and sporadic malignant breast tissues was investigated using a polyclonal (ATM-4BA) and a monoclonal (CT-1) antibody, both of which detect a single $350 \mathrm{kDa}$ protein in western analyses of normal cells. ${ }^{19}$ Strong ATMimmunoreactivity was found in 36 of the 42 normal tissue samples. ATM labelling was found predominantly in the cytoplasm of cells within the inner epithelial layer of normal breast ducts. Although it is not surprising that nuclear immunostaining is found in the normal ductal epithelial cells in some cases, given that the ATM gene has an important regulatory role in the cell cycle, ${ }^{10}{ }^{11}{ }^{13}$ the importance of this finding in normal breast tissue is uncertain. Moreover, it has been shown previously that the ATM protein is localised to both the nuclei and cytoplasm of normal fibroblasts and stimulated lymphoid cells. ${ }^{19}$

Most metastatic breast carcinomas in lymph nodes (10 of 14) had greatly reduced or absent ATM protein production, which was significant when compared with that observed in pri- 
mary invasive breast carcinomas $(\mathrm{p}=0.029$; $\chi^{2}$ with continuity correction). Although no significant difference in ATM production was found between sporadic primary IDCs and normal tissues of the breast ( $p=0.073 ; \chi^{2}$ with continuity correction), a large proportion of the primary carcinomas (14 of 42) also had reduced or absent ATM protein immunoreactivity. There was a consistent trend towards weaker ATM immunostaining for more invasive stages between patients (table 1) and within all patients with progressive stages of breast cancer (table 2).

Our results suggest that ATM synthesis is downregulated or silenced in most of the axillary lymph node metastases. However, the normal PTT results for three patients (fig 2) with negligible ATM immunostaining in metastases, and in a larger number of patients with breast cancer investigated elsewhere ${ }^{26}$ suggest that this reduced ATM immunoreactivity is unlikely to be related to ATM gene mutations. ${ }^{18}{ }^{26}$ We have shown previously that the ATM gene can be upregulated in the myoepithelium surrounding normal breast ducts. ${ }^{25}$ Previous population studies have shown LOH around the ATM gene locus on chromosome $11 \mathrm{q} 23$ in $47 \%$ of IDC $^{18}$ and $59 \%$ of metastases. ${ }^{26}$ Our results parallel and support these $\mathrm{LOH}$ data, which presumably reflect genomic rearrangements around $11 \mathrm{q} 23$. Genomic rearrangements are common during tumorigenesis, as are other forms of allelic silencing, such as hypermethylation of $\mathrm{CpG}$ islands within gene promoters. ${ }^{18} 2728$ The putative downregulation or silencing of ATM described here might be the result of more than one of these mechanisms.

The fact that downstream tumorigenic alterations to the genome might contribute to ATM downregulation does not alter the fact that these results were consistent with the established tumour suppressor role of ATM. The increased radiosensitivity and incidence of breast cancer in A-T heterozygotes with null mutations is presumably the result of haploinsufficiency of the ATM tumour suppressor. ${ }^{14-629}$ This, together with the inverse correlation described here between the levels of ATM gene expression and the stage of tumour progression, supports the proposition that reduced concentrations of ATM might be implicated in breast cancer, with unknown implications for tumour radioresponsiveness. In addition, the nuclear expression of the ATM gene is consistent with the DNA damage response role of ATM and this might be important in early and/or later stages of tumour suppression. The cytoplasmic localisation of the ATM protein is suggestive of additional roles for ATM, some of which might also be implicated in tumorigenesis.

In summary, our study reports on the immunohistological localisation of the ATM protein in paraffin wax embedded sections of normal human breast tissue and breast carcinoma. ATM protein immunoreactivity was strongest in the cytoplasm of normal breast epithelium, reduced in a small proportion of sporadic breast carcinomas, and dramatically reduced in most deposits of metastatic breast carcinomas in axillary lymph nodes. The level of ATM protein production was inversely correlated with tumour invasiveness. Our results are consistent with the tumour suppressor role of ATM and might implicate ATM in sporadic breast carcinoma progression.

1 Easton DF. Cancer risk in A-T heterozygotes. Int $\mathcal{f}$ Radiat Biol 1994;66:177-82.

2 Gatti RA, Berkel I, Boder E, et al. Localisation of the ataxiatelangiectasia gene to chromosome 11q22-23. Nature 1988;336:577-80.

3 Lavin MF, Shiloh Y. The genetic defect in ataxiatelangiectasia. Annu Rev Immunol 1997;15:177-202.

4 Swift M, Reitnauer PJ, Morrell D, et al. Breast and other cancers in families with ataxia-telangiectasia. $\mathrm{N} \mathrm{Engl} \mathrm{f} \mathrm{Med}$ 1987;316:1289-94.

5 Swift M, Morrell D, Massey RB, et al. Incidence of cancer in 161 families affected by ataxia-telangiectasia. $N$ Engl F Med 1991;325:1831-6.

6 Athma P, Rappaport R, Swift M. Molecular genotyping shows that ataxia-telangiectasia heterozygotes are predisposed to breast cancer. Cancer Genet Cytogenet 1996;92:130-4.

7 Bishop DT, Hopper J. A-T-tributable risks? Nat Genet 1997; 15:226.

8 Fitzgerald MG, Bean JM, Hedge SR, et al. Heterozygous ATM mutations do not contribute to early onset breast ATM mutations do not contribute
cancer. Nat Genet 1997;5:307-10.

9 Savitsky K, Bar-Shira A, Gilad S, et al. A single ataxia-telangiectasia gene with a product similar to PI-3 kinase. Science 1995;268:1749-53.

10 Kastan MB, Zhan O, El-Deiry WS, et al. A mammalian cell cycle checkpoint pathway utilizing p53 and GADD45 is defective in ataxia-telangiectasia. Cell 1992;71:587-97.

11 Khanna KK, Beamish H, Yan J, et al. Nature of G1/S cell cycle checkpoint defect in ataxia-telangiectasia. Oncogene
1995;11:609-18.

12 Savitsky K, Sfez S, Tagle DA, et al. The complete sequence of the coding region of the ATM gene reveals similarity to cell cycle regulators in different species. Hum Mol Genet cell cycle regulators

13 Canman CE, Wolff AC, Chen CY, et al. The p53-dependent G1 cell cycle checkpoint pathway and ataxia-telangiectasia. Cancer Res 1994;54:5054-8.

14 Byrd PJ, McConville CM, Cooper P, et al. Mutations revealed by sequencing the $5^{\prime}$ half of the gene for ataxia-telangiectasia. Hum Mol Genet 1996;5:145-9.

15 Telatar M, Wang Z, Udar W, et al. Ataxia telangiectasia: mutations in cDNA detected by protein truncation screening. Am F Hum Genet 1996;59:40-4.

16 Gilad S, Khosravi R, Shkedy D, et al. Predominance of null mutations in ataxia-telangiectasia. Hum Mol Genet 1996;5: 433-40.

17 Man S, Ellis IO, Sibbering M, et al. High levels of allele loss at the FHIT and ATM genes in non-comedo ductal carciat the FHIT and ATM genes in non-comedo ductal carcinoma in situ and grade I tubul

18 Vorechovsky I, Rasio D, Luo L, et al. The ATM gene and susceptibility to breast cancer: analysis of 38 breast tumours reveals no evidence for mutation. Cancer Res 1996;56:2726-32.

19 Watters D, Khanna KK, Beamish H, et al. Cellular localisation of the ataxia telangiectasia (ATM) gene product and discrimination between mutated and normal forms. Oncogene 1997;14:1911-21.

20 Boenisch T. Staining methods. In: Naisch SJ, ed. Handbook of immunochemical staining methods. California: DAKO Corporation, 1989:16-18.

21 Elston CW, Ellis IO. Pathological prognostic factors in breast cancer I. The value of histological grade in breast cancer: experience from a large study with long term follow-up. Histopathology 1992;19:403-10.

22 Roest PAM, Roberts RG, Sugino S, et al. Protein truncation test (PTT) for rapid detection of translation-terminating mutations. Hum Mol Genet 1993;2:1719-21.

23 Clarke RA, Goozee G, Birrell G, et al. Absence of ATM truncation mutations in patients with severe acute radiation reactions. Int 7 Radiat Oncol Biol Phys 1998;41:1021-7.

24 Vorechovsky I, Luo L, Dyer MJS, et al. Clustering of missense mutations in the ataxia-telangiectasia gene in a missense mutations in the ataxia-telangiectasia gene

25 Clarke RA, Kairouz R, Watters D, et al. Up-regulation of ATM in sclerosing adenosis in the breast. F Clin Pathol: Mol Pathol 1998;51:224-6.

26 Tomlinson IPM, Stickland JE, Lee ASG, et al. Loss of heterozygosity on chromosome $11 \mathrm{q}$ in breast cancer. $\mathcal{F}$ Clin Pathol 1995;48:424-8.

27 Sakai T, Toguchida J, Ohtani N, et al. Allele-specific hypermethylation of the retinoblastoma tumor-supressor gene. Am f Hum Genet 1991;48:880-8.

28 Gonzalez-Zulueta M, Bender CM, Yang AS, et al. Methylation of the $5^{\prime} \mathrm{CpG}$ island of the p16/CDKN2 tumor suppressor gene in normal and transformed human tissues correlates with gene silencing. Cancer Res 1995;55:4531-5.

29 Borreson AL, Andersen TI, Treti S, et al. Breast cancer and other cancers in Norwegian families with ataxiatelangiectasia. Genes Chromosomes Cancer 1990;2:339-40. 